Int. J. Electrochem. Sci., 14 (2019) $4206-4215$

\title{
Self-Assembled Monolayers of Alkanethiol as Inhibitors against Copper Corrosion in Synthetic Acid Rain
}

\author{
Ivana Martinović*, Gloria Zlatić, Zora Pilić, Lucija Šušić, Olga Kowalska, Danijel Petrović, \\ Franjo Falak, Josip Mišković \\ Department of Chemistry, Faculty of Science and Education, University of Mostar, Mostar, Bosnia and \\ Herzegovina \\ *E-mail: ivana.martinovic@fpmoz.sum.ba
}

doi: $10.20964 / 2019.05 .28$

Received: 9 January 2019 / Accepted: 4 March 2019 / Published: 10 April 2019

The adsorption and corrosion inhibition of alkanethiols self-assembled monolayer on the copper surface in simulated acid rain were investigated by electrochemical techniques. Self-assembled monolayer (SAM) was formed by 1-octanethiol (OT), 1-dodecanethiol (DT) and 1-octadecanethiol (ODT) molecules on copper surface. The experimental results showed that inhibiton efficiency increases simultaneously with increase of concentration and chain length of thiols. At the concentration of $0.5 \mathrm{mmol} \mathrm{L}{ }^{-1}$, 1-octadecanethiol (ODT) acts as effective corrosion inhibitor with inhibition efficiency of $\sim 90 \%$. The adsorption of alkanethiol self-assembled monolayer on the copper surface was investigated by polarization measurements. The adsorption of SAMs on the copper surface followed Langmuir isotherm and the standard Gibbs energy indicated that the adsorption mechanism of OT, DT and ODT on copper is the hybrid type of physical and chemical adsorption. Values of Gibbs energy ranging from $-24 \mathrm{~kJ} \mathrm{~mol}^{-1}$ for OT to $-32 \mathrm{~kJ} \mathrm{~mol}^{-1}$ for ODT indicate that the chemisorption part in the adsorption mechanism prevails with the increase of alkanethiols chain length.

Keywords: self-assembled monolayer; copper; acid rain; electrochemical techniques

\section{$\underline{\text { FULL TEXT }}$}

(C) 2019 The Authors. Published by ESG (www.electrochemsci.org). This article is an open access article distributed under the terms and conditions of the Creative Commons Attribution license (http://creativecommons.org/licenses/by/4.0/). 